\title{
Article \\ Preparation and Properties of Directionally Solidified Ni-Al Based Alloys Modified by Molybdenum
}

\author{
Jitka Malcharcziková ${ }^{1, * \mathbb{D}}$, Kateřina Skotnicová ${ }^{1} \mathbb{D}$, Petr Kawulok ${ }^{2} \mathbb{D}$, Rostislav Kawulok $^{2}$ KD $_{\text {, Ivo Szurman }}{ }^{1}$ \\ and Jana Růžička ${ }^{1}$
}

check for

updates

Citation: Malcharcziková, J.;

Skotnicová, K.; Kawulok, P.;

Kawulok, R.; Szurman, I.; Růžička, J.

Preparation and Properties of

Directionally Solidified Ni-Al Based

Alloys Modified by Molybdenum

Crystals 2022, 12, 215. https://

doi.org/10.3390/cryst12020215

Academic Editors: Qian Wang,

Wei Fu, Feng Jin, Min Lei

and Junmiao Shi

Received: 7 January 2022

Accepted: 29 January 2022

Published: 31 January 2022

Publisher's Note: MDPI stays neutral with regard to jurisdictional claims in published maps and institutional affiliations.

Copyright: (C) 2022 by the authors. Licensee MDPI, Basel, Switzerland. This article is an open access article distributed under the terms and conditions of the Creative Commons Attribution (CC BY) license (https:// creativecommons.org/licenses/by/ $4.0 /)$
1 Department of Non-Ferrous Metals, Refining and Recycling, Faculty of Materials Science and Technology, VŠB-Technical University of Ostrava, 17. listopadu 2172/15, 70800 Ostrava, Czech Republic; katerina.skotnicova@vsb.cz (K.S.); ivo.szurman@vsb.cz (I.S.); jana.hascinova@vsb.cz (J.R.)

2 Department of Materials Forming, Faculty of Materials Science and Technology, VŠB-Technical University of Ostrava, 17. listopadu 2172/15, 70800 Ostrava, Czech Republic; petr.kawulok@vsb.cz (P.K.); rostislav.kawulok@vsb.cz (R.K.)

* Correspondence: jitka.malcharczikova@vsb.cz; Tel.: +420-596-993-312

\begin{abstract}
Ni-Al-Mo based alloys can be used as materials for high temperature applications. They can be prepared by various techniques such as an electron beam zone melting, which allows us to obtain the alloys with a directionally solidified structure and unique properties. A plasma-melted Ni-Mo master alloy was used for the preparation of the experimental alloys. Ni-Al-Mo alloys were melted in an induction furnace and then cast centrifugally in the form of bars. These bars were then re-melted in the electron beam zone furnace. The structure of these alloys was multi-phase. The structure was formed by the phases $\mathrm{Ni}_{3}(\mathrm{Al}, \mathrm{Mo})$ and $(\mathrm{Ni})$ with variable content of molybdenum. The structure also contained particles rich in molybdenum (Mo, MoNi). The alloys were submitted to the compression tests at a temperature of $800{ }^{\circ} \mathrm{C}$. The yield strength of alloys achieved the value of approx. $800 \mathrm{MPa}$. The different molybdenum content affected the values of the maximal flow stress. The alloys with higher molybdenum content showed higher maximal flow stress, namely approx. $1300 \mathrm{MPa}$. The results show that these alloys are very promising for the production of structural components operating at elevated temperatures.
\end{abstract}

Keywords: $\mathrm{Ni}_{3} \mathrm{Al}$ based alloys; plasma melting; electron beam zone melting; hot compression tests

\section{Introduction}

Ni-Al-Mo based alloys can be used as materials for high temperature applications. Nickel super alloys are widely used on an industrial scale, whereas $\mathrm{Ni}_{3} \mathrm{Al}$-based alloys are used less frequently. These alloys, such as IC50, IC221M or IC6SX, can be used for less demanding applications. Their advantage is lower density and sufficient corrosion resistance [1-3]. They can be prepared using various techniques based on the melting and casting of initial pure metals or master alloys followed by the special re-melting process such as electron beam floating zone melting (EBFZM). This process enables us to obtain the directionally solidified structure of these alloys showing the unique properties compared to the cast state. The structure of the alloys used is still evolving and it is common today to use alloys in monocrystalline form for the specific applications of this type of alloys, whereas there is also interest in less alloyed alloys. An example is the IC6SX alloy based on Ni-Al-Mo, which in monocrystalline form has a very promising composite structure [4-6]. Alloys can be prepared by directional solidification (DS) using the Bridgman method or by electron beam floating zone melting. This method allows for highly efficient growing of single crystals of $\mathrm{Ni}_{3} \mathrm{Al}$ alloys based on IC6SX. The main alloying element in this case is molybdenum and, optionally, boron is also used [4-7]. Molybdenum ensures the growth of so-called fibres along the length of the crystal. The alloy then acts as a metal matrix composite (MMC), exhibiting special properties and allowing expensive alloys to 
be replaced in adequate applications (e.g., blades). The possibility of further influencing the resulting structure, e.g., by heat treatment, is still being verified [8]. Creep behaviour of these alloys under various conditions (500-580 MPa at $760{ }^{\circ} \mathrm{C}$ or $180-230 \mathrm{MPa}$ ) was investigated in $[9,10]$. It was found, when the stress increased from $180 \mathrm{MPa}$ to $230 \mathrm{MPa}$, the creep life decreased from $245.5 \mathrm{~h}$ to $69.3 \mathrm{~h}$ at $980^{\circ} \mathrm{C}$. With the stress increasing from $500 \mathrm{MPa}$ to $580 \mathrm{MPa}$, the creep life decreased from more than $1000 \mathrm{~h}$ to $32.64 \mathrm{~h}$ at $760{ }^{\circ} \mathrm{C}$.

The aim of our study was to prepare and complex characterize the low-alloyed $\mathrm{Ni}$ alloys based on intermetallic $\mathrm{Ni}_{3} \mathrm{Al}$ compound in directionally solidified state intended for high temperature applications. It is expected that modification of these alloys by molybdenum and usage of special re-melting methods will lead to the formation of in-situ metal matrix composite with increased mechanical properties.

\section{Materials and Methods}

Experimental alloys with a nominal composition of Ni-8Al-14Mo (samples A, wt.\%) and $\mathrm{Ni}-8 \mathrm{Al}-20 \mathrm{Mo}$ (samples $\mathrm{B}$, wt.\%) were prepared by induction melting with centrifugal casting (CC) under a protective atmosphere of Ar using a Supercast-Titan induction furnace (Linn High Therm GmbH, Eschenfelden, Germany). As raw/input materials, the Ni-Mo master alloy and pure $\mathrm{Ni}(99.9 \%)$ and $\mathrm{Al}(99.99 \%)$ metals were used. A master alloy with the composition $\mathrm{Ni}-47 \mathrm{Mo}$ (wt.\%) was prepared using a high temperature plasma furnace (VacuumTech, Ltd., Prague, Czech Republic). The composition was chosen according to the binary diagram [11] so as to ensure a sufficient molybdenum content for the preparation of alloys and that the master alloy would not have a very high melting point. The structure of the master alloy consisted of two phases-lighter phase of $\mathrm{Mo}_{7} \mathrm{Ni}_{7}$ and a darker phase $\mathrm{MoNi}_{3}$ (Figure 1). The prepared rods (Figure 2) with a diameter of $10 \mathrm{~mm}$ and a length of $200 \mathrm{~mm}$ were subsequently re-melted in a vacuum of the order of $10^{-4} \mathrm{~Pa}$ at two different rates of 20 and $50 \mathrm{~mm} / \mathrm{h}$ using a DI EPV 6000 electron beam zone furnace (DELONG INSTRUMENTS a. s., Brno, Czech Republic) to obtain the directed structure of these alloys. The melting zone a few millimetres wide was positioned in the vertical direction, from the bottom up. The rods placed in the furnace and the shape of the re-melted zone are shown in Figure 3. The microstructure and chemical composition of the prepared alloys in as-cast state and after the directional solidification (as-directed state), and master alloy were studied by scanning electron microscopy (SEM) using a QUANTA 450 FEG (FEI Company, Hillsborough, OR, USA) equipped with an energy-dispersive X-ray (EDX) APOLLO X analyser. The images were taken in the backscattered electron mode (BSE).

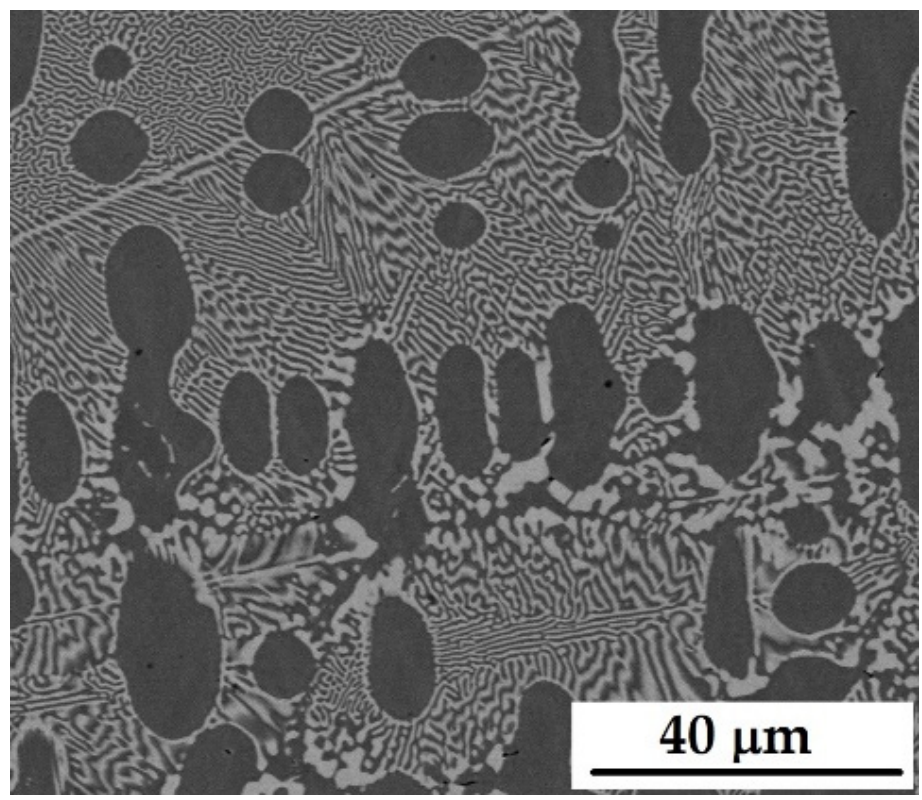

Figure 1. Structure of master alloy Ni-Mo. 


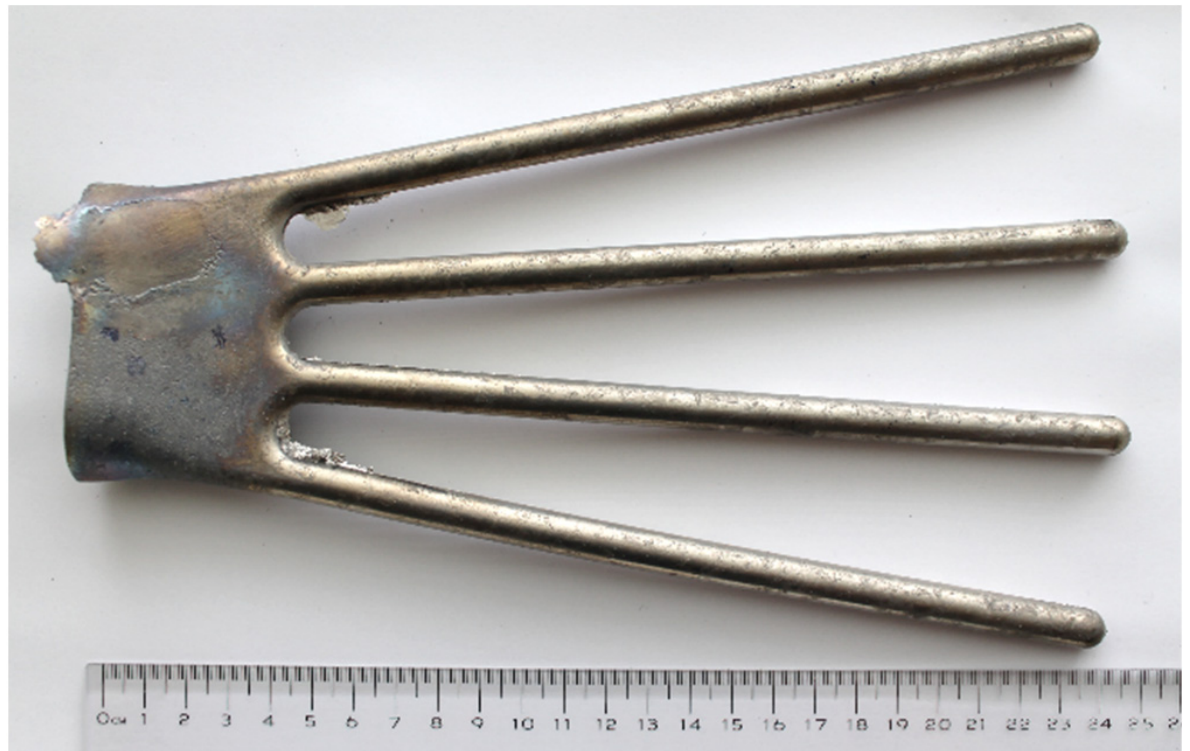

Figure 2. Casting of Ni-Al-Mo alloy.

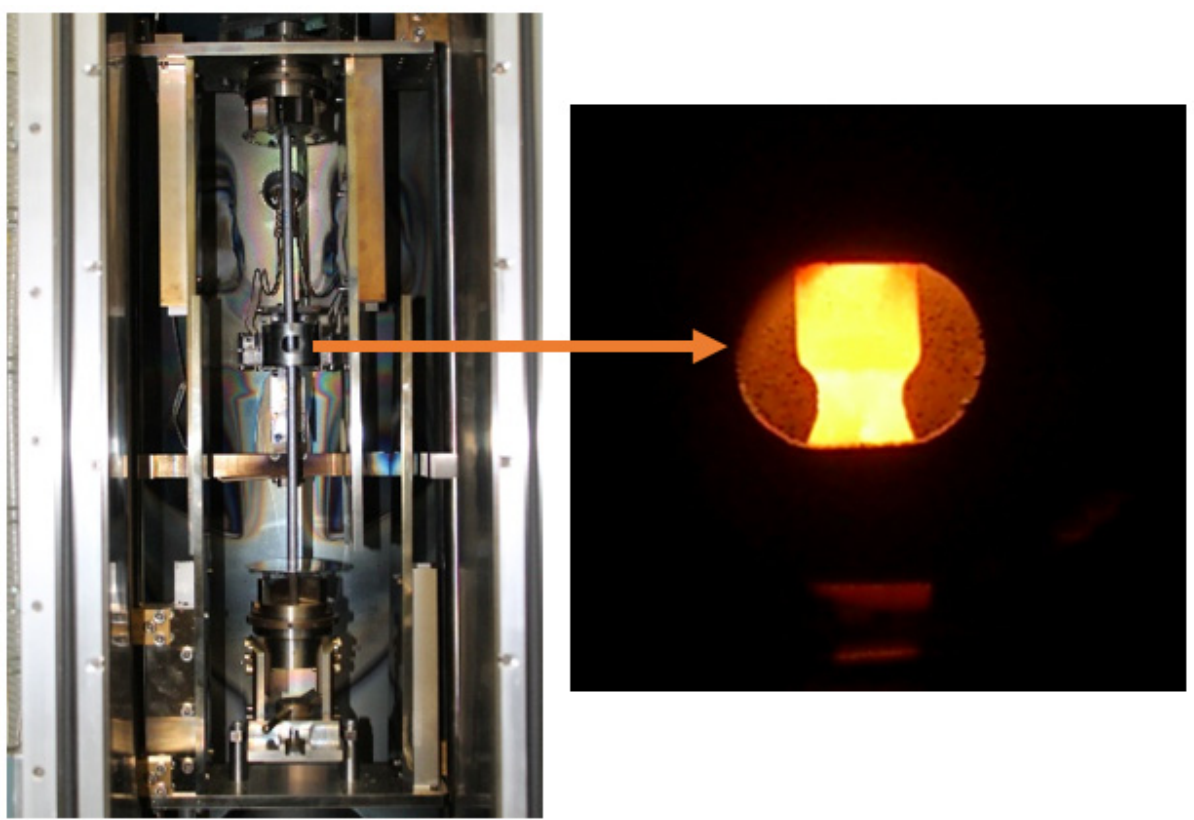

Figure 3. The placement of sample in the EBFZM furnace and the shape of melting zone.

The chemical composition and process parameters of prepared alloys and sample identification are given in Table 1. According to literature data [12], this composition should lead to the formation of the required phases $\gamma-\mathrm{Ni}(\mathrm{Mo}), \gamma^{\prime}-\mathrm{Ni}_{3}(\mathrm{Al}, \mathrm{Mo})$ and Mo-rich phase. The structure of these alloys can be further effectively modified using various methods-heat treatment or directional solidification.

Table 1. Characterization of prepared alloys and sample identification.

\begin{tabular}{ccc}
\hline Sample & $\begin{array}{c}\text { Composition } \\
\text { (wt.\%) }\end{array}$ & $\begin{array}{c}\text { Zone Pass Rate } \\
(\mathbf{m m} / \mathbf{h})\end{array}$ \\
\hline A20 & Ni-8Al-14Mo & 20 \\
A50 & Ni-8Al-14Mo & 50 \\
B20 & Ni-8Al-20Mo & 20 \\
B50 & Ni-8Al-20Mo & 50 \\
\hline
\end{tabular}




\section{Results}

\subsection{Microstructural Characterization of Alloys}

The microstructure of the experimental alloys was investigated both in the initial as-cast state and after the process of directional solidification (as-directed state). It can be seen from Figure 4 (Ni-8Al-14Mo alloy, samples A) and Figure 5 (Ni-8Al-20Mo alloy, samples B) that the structure of the alloys in cross-sections is dendritic in both cases and the grains are oriented in the direction of growth.

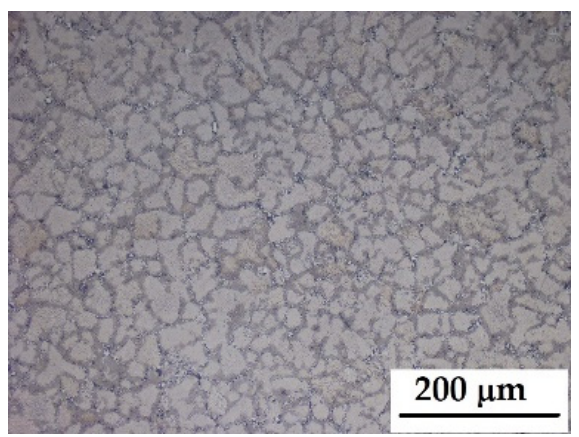

(a)

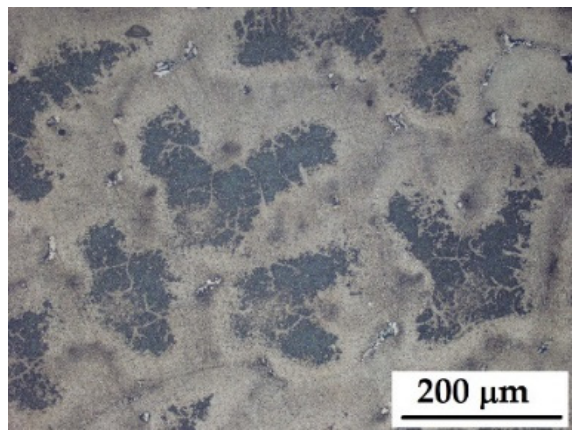

(b)

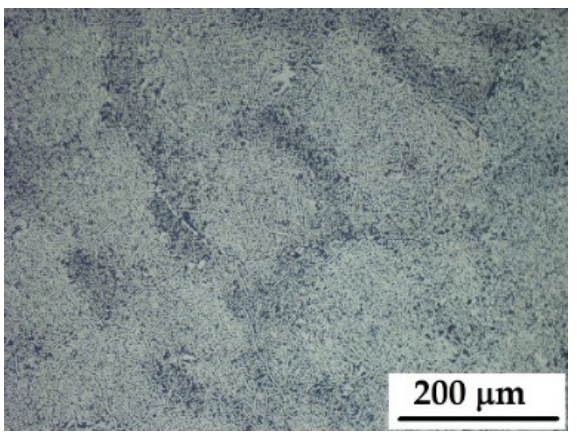

(c)

Figure 4. Structure of sample A: (a) Sample A-as-cast state; (b) Sample A50 after DS at rate $50 \mathrm{~mm} / \mathrm{h}$; (c) Sample A20 after DS at rate $20 \mathrm{~mm} / \mathrm{h}$.

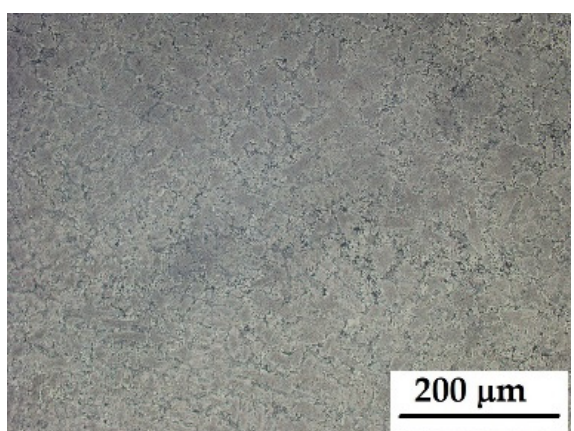

(a)

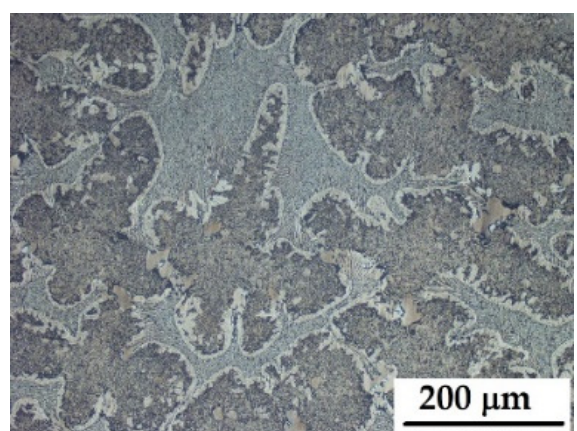

(b)

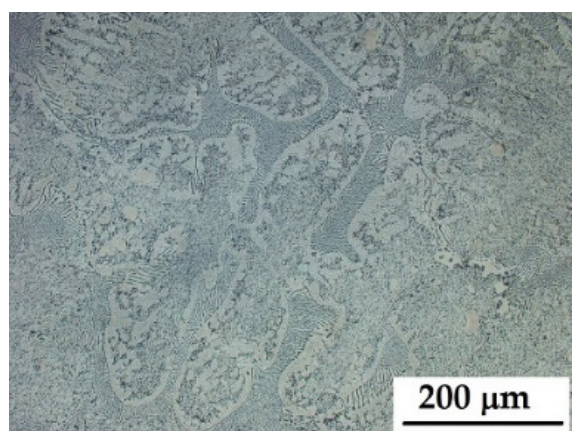

(c)

Figure 5. Structure of sample B: (a) Sample B-as-cast state; (b) Sample B50 after DS at rate $50 \mathrm{~mm} / \mathrm{h}$; (c) Sample B20 after DS at rate $20 \mathrm{~mm} / \mathrm{h}$.

The results of spot chemical analysis are summarized in Table 2. In all cases, these alloys represented multiphase systems, where the detected phases contained different ratios of alloying elements. The microstructure of alloys after the directional solidification consisted of $\mathrm{Ni}_{3}(\mathrm{Al}, \mathrm{Mo})$ and $(\mathrm{Ni})$ phases with variable molybdenum content. Molybdenumrich particles (Mo, MoNi) were also observed in the structure. Figures 6 and 7 show the microstructures of samples A and B. Two-phase regions $\gamma / \gamma^{\prime}$ (spot 1) consisting of a darker phase $\gamma^{\prime}\left(\mathrm{Ni}_{3} \mathrm{Al}\right)$ and lighter regions of the phase $\gamma(\mathrm{Ni})$ were visible. These areas, referred to as network, contained a certain proportion of Mo, as shown in Table 2. The composition of the individual phases in the network cannot be analysed by EDS technique due to their small size. For this reason, the chemical composition was determined as the average values of content of the alloying element in these areas. Furthermore, dark grey areas occurring in the alloy structure correspond to the $\gamma^{\prime}-\mathrm{Ni}_{3}(\mathrm{Al}, \mathrm{Mo}$ ) phase (spot 2). The very light areas (spot 3) in Figures 6 and 7 correspond to the molybdenum-rich phases. In sample A50, the light phases in Figure 6a were identified as $\delta$-NiMo phases. This phase can occur in alloys of this composition in the cast state, as mentioned in $[12,13]$. Due to the low rate of solidification, this phase can be expected to occur in this sample as well. However, the light 
phases of this sample have small dimensions that make measurement difficult. The very light areas (spot 3) in the samples A20, B50 and B20 was identified as solid solution of Ni and $\mathrm{Al}$ in molybdenum. In [14] the composition of Mo fibres was stated Mo-4.0Ni-9.96Al (at.\%) for NiAl-Mo alloy with content of 13 at.\% Mo, which is similar to our case. The results obtained from the point analysis of the chemical composition of individual phases might be influenced by the environment for phases with very small dimensions. These observed phases corresponded to data from the thermodynamic modelling of the ternary $\mathrm{Ni}$-Al-Mo system [15]. However, the phase composition of individual samples can be affected by the crystallization conditions (zone pass rate). It is assumed that in the first phase of solidification a solid solution $\gamma$ with different contents of $\mathrm{Al}$ and $\mathrm{Mo}$ is formed. Subsequently, other $\gamma^{\prime}-\mathrm{Ni}_{3}(\mathrm{Al}, \mathrm{Mo})$ and Mo-rich phases were formed. It should be noted that the lower molybdenum content and higher solidification rate led to the formation of $\delta$-NiMo phase.

Table 2. The results of spot chemical analysis of Samples A and B.

\begin{tabular}{ccccc}
\hline \multicolumn{5}{c}{ Composition (at.\%) } \\
\hline Element & A50 & A20 & B50 & B20 \\
\hline \multicolumn{5}{c}{ Analysis from point 1 } \\
\hline $\mathrm{Ni}$ & $72.3 \pm 0.5$ & $71.5 \pm 0.3$ & $70.0 \pm 0.4$ & $71.1 \pm 0.0$ \\
$\mathrm{Al}$ & $17.9 \pm 1.0$ & $11.6 \pm 0.3$ & $20.1 \pm 0.2$ & $19.67 \pm 0.0$ \\
$\mathrm{Mo}$ & $9.8 \pm 1.6$ & $16.9 \pm 0.0$ & $9.9 \pm 0.2$ & $9.3 \pm 0.1$ \\
\hline \multicolumn{5}{c}{ Analysis from point 2 } \\
$\mathrm{Ni}$ & $72.9 \pm 0.0$ & $72.3 \pm 0.2$ & $71.5 \pm 0.1$ & $72.1 \pm 0.2$ \\
$\mathrm{Al}$ & $22.6 \pm 0.0$ & $23.5 \pm 0.4$ & $24.6 \pm 0.0$ & $24.0 \pm 0.3$ \\
$\mathrm{Mo}$ & $4.5 \pm 0.0$ & $4.2 \pm 0.3$ & $3.9 \pm 0.1$ & $4.0 \pm 0.0$ \\
\hline \multicolumn{5}{c}{ Analysis from point 3 } \\
$\mathrm{Ni}$ & $46.4 \pm 1.3$ & $6.1 \pm 0.1$ & $5.8 \pm 0.2$ & $5.0 \pm 0.0$ \\
$\mathrm{Al}$ & $2.7 \pm 0.9$ & $1.7 \pm 0.2$ & $3.0 \pm 0.1$ & $2.3 \pm 0.2$ \\
$\mathrm{Mo}$ & $50.9 \pm 0.4$ & $92.2 \pm 0.3$ & $91.2 \pm 0.3$ & $92.8 \pm 0.0$ \\
\hline
\end{tabular}

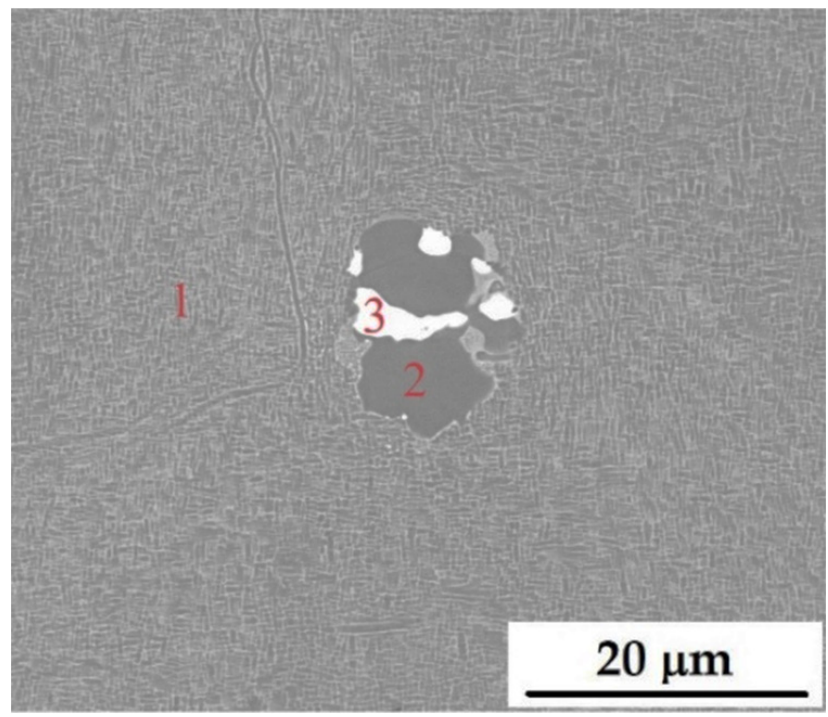

(a)

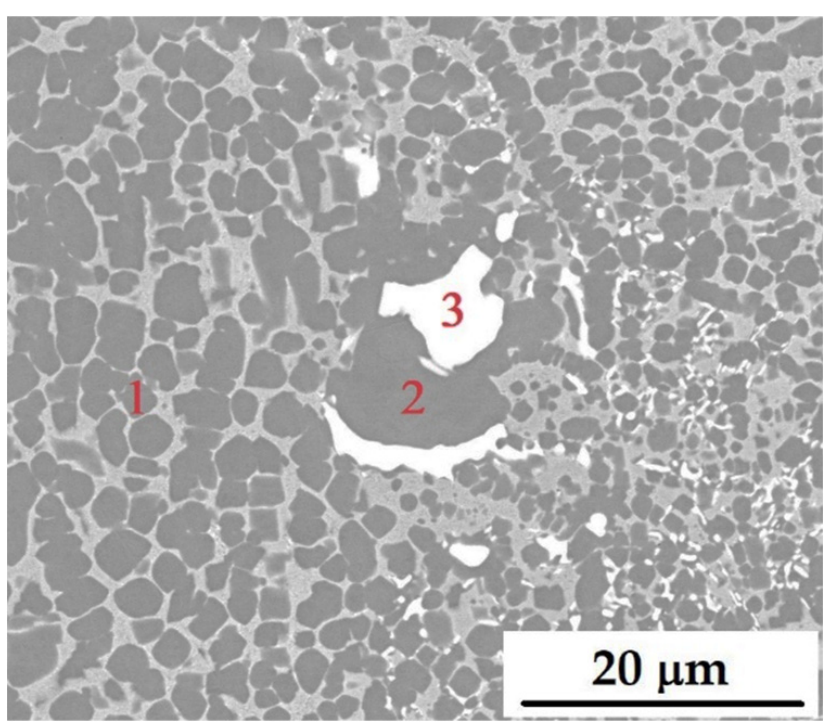

(b)

Figure 6. Microstructure of sample A: (a) Sample A50 after DS at rate $50 \mathrm{~mm} / \mathrm{h}$; (b) Sample A20 after DS at rate $20 \mathrm{~mm} / \mathrm{h} ; 1$-two-phase regions $\gamma / \gamma^{\prime}, 2-\gamma^{\prime}-\mathrm{Ni}_{3}(\mathrm{Al}, \mathrm{Mo})$ phase, 3-Mo-rich phases. 


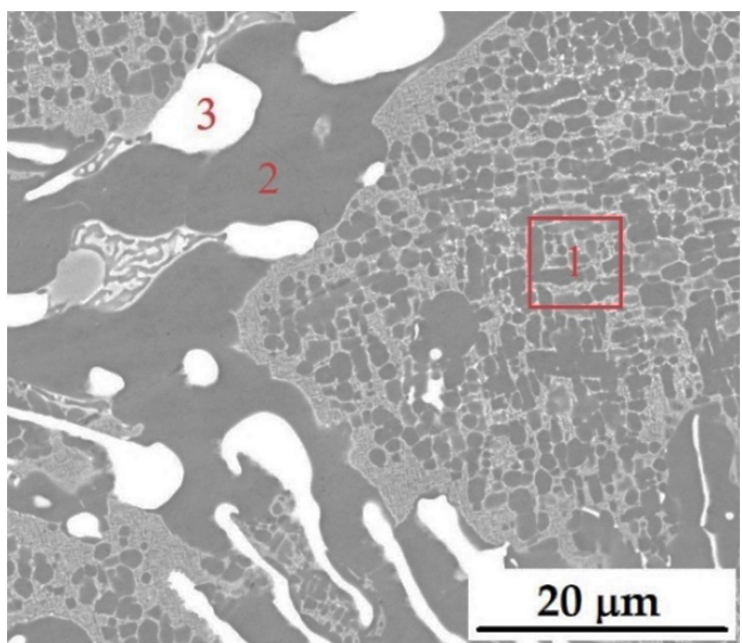

(a)

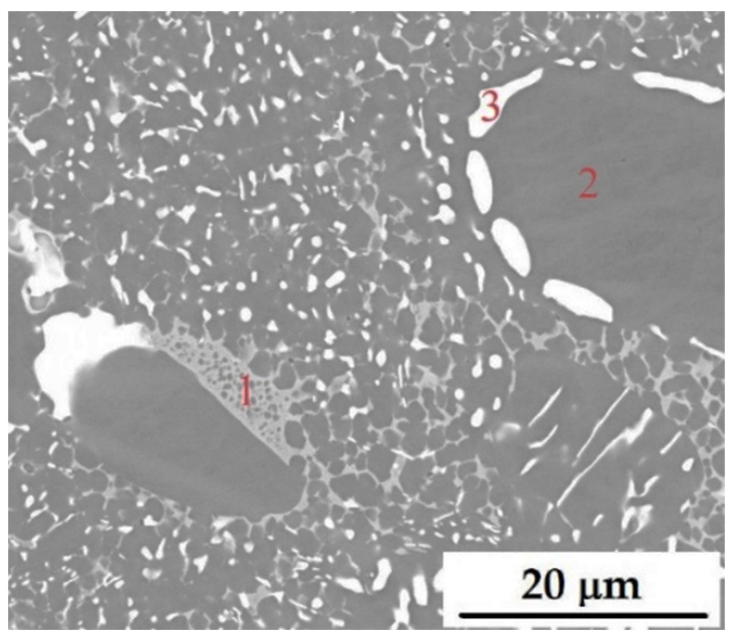

(b)

Figure 7. Microstructure of sample B: (a) Sample B50 after DS at rate $50 \mathrm{~mm} / \mathrm{h}$; (b) Sample B20 after DS at rate $20 \mathrm{~mm} / \mathrm{h} ; 1$-two-phase regions $\gamma / \gamma^{\prime}, 2-\gamma^{\prime}-\mathrm{Ni}_{3}(\mathrm{Al}, \mathrm{Mo})$ phase, 3-Mo-rich phases.

The preparation of these alloys is controlled mainly by two parameters. The first parameter is one-way heat dissipation, the second is the ability to maintain a high temperature gradient (high solidification rate). The zone pass rate does not directly correspond to the solidification rate. At a slower zone pass rate of $20 \mathrm{~mm} / \mathrm{h}$, light Mo-rich formations were visible in the structure. In sample A20 with a slower zone pass rate, coarser phases occurred, light Mo-rich phases were present as larger formations with a size of about $10-15 \mu \mathrm{m}$ and finer dispersed particles up to $1 \mu \mathrm{m}$, which is visible in Figure $6 \mathrm{~b}$ at the bottom right. In sample B50 with a higher molybdenum content, larger light Mo-rich phases of about 5-20 $\mu \mathrm{m}$ were observed. In sample B20 prepared with a slower zone pass rate, there were again bright Mo-rich coarser phases with a size of about $5-10 \mu \mathrm{m}$ and finely dispersed smaller particles in the region between points 1 and 3 in Figure $7 \mathrm{~b}$ of approx. $1 \mu \mathrm{m}$. This resulting structure best corresponds to the presumed type of structure with the occurrence of dispersed Mo-strengthening phases [12].

\subsection{Mechanical Properties of Alloys}

The alloys in a directionally solidified state were subjected to the compression test. Uniaxial compression tests were performed on a Gleeble 3800 plastometer. Cylindrical samples with diameter of $8 \mathrm{~mm}$ and height of $12 \mathrm{~mm}$ were prepared for these purposes. The samples were heated (by electrical resistant heating) at a rate of $3{ }^{\circ} \mathrm{C} \mathrm{s}^{-1}$ to uniform deformation temperature $800^{\circ} \mathrm{C}$, and after $15 \mathrm{~s}$ holding time they were deformed by uniaxial compression up to a true (logarithmic) strain of 0.53 at a uniform constant strain rate $5 \cdot 10^{-2} \mathrm{~s}^{-1}$. Figure 8 shows the samples after the uniaxial compression tests. The measured flow stress curves for alloys with different molybdenum contents solidified at 50 and $20 \mathrm{~mm} / \mathrm{h}$ are shown in Figure 9. The values of yield strength YS (MPa), maximal achieved flow stress $\sigma_{\max }(\mathrm{MPa})$ and peak strain $\varepsilon_{\mathrm{p}}(-)$, which corresponds to maximal flow stress, were determined from the course of flow stress curves (see Figure 9) and they are summarized in Table 3.

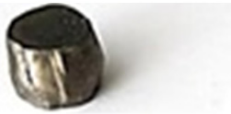

A50

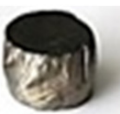

A20

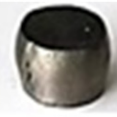

B50

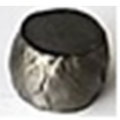

B20

$10 \mathrm{~mm}$

Figure 8. The samples after compression test. 


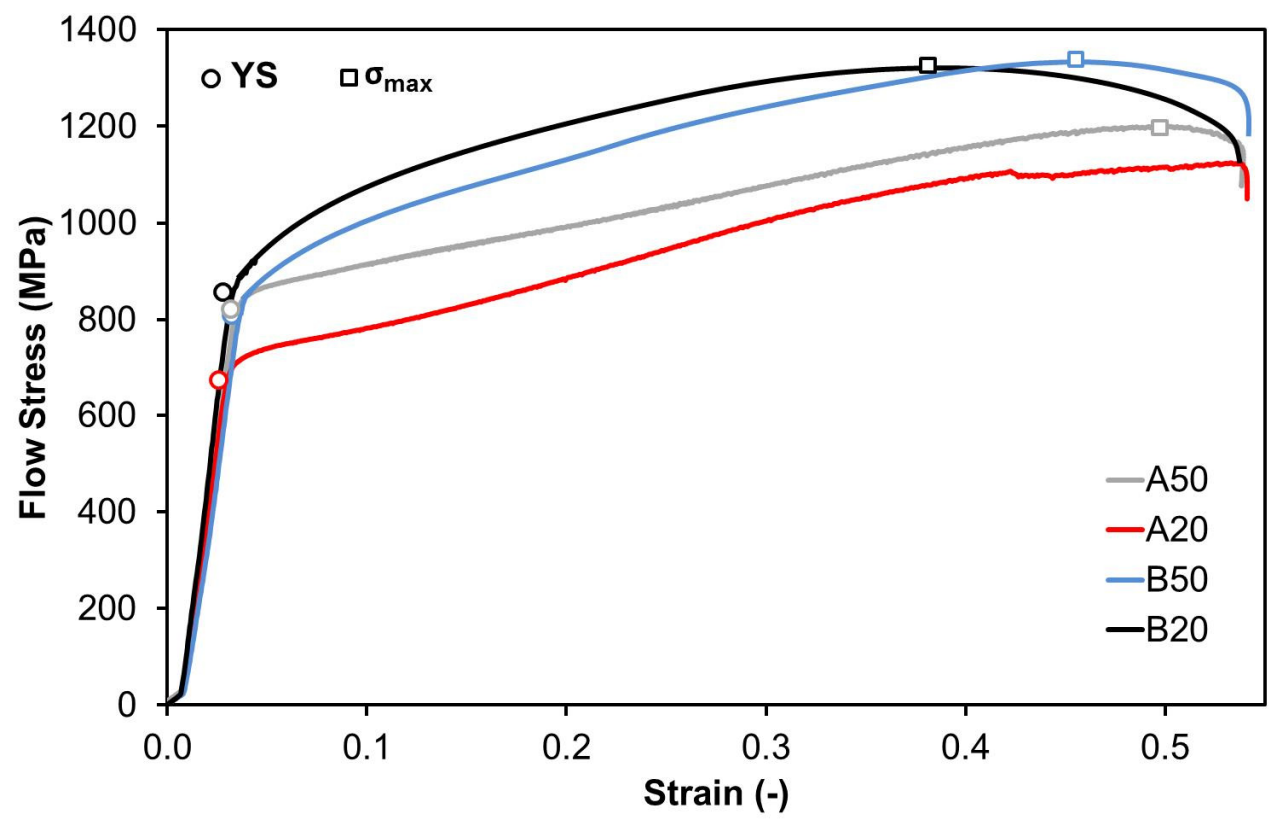

Figure 9. The measured flow stress curves of investigated alloys.

Table 3. Results of uniaxial compression tests of investigated alloys.

\begin{tabular}{cccc}
\hline Sample & $\begin{array}{c}\text { YS } \\
(\mathbf{M P a})\end{array}$ & $\begin{array}{c}\boldsymbol{\sigma}_{\max } \\
(\mathbf{M P a})\end{array}$ & $\begin{array}{c}\varepsilon_{\mathbf{p}} \\
(-\boldsymbol{)}\end{array}$ \\
\hline A50 & 820 & 1199 & 0.50 \\
A20 & 680 & $\mathrm{~N} / \mathrm{A}$ & $\mathrm{N} / \mathrm{A}$ \\
B50 & 815 & 1339 & 0.46 \\
B20 & 855 & 1330 & 0.38 \\
\hline
\end{tabular}

It can be seen that the curves have a similar character and the alloys were further strengthened to high strain values after reaching the yield point. The yield strengths $Y S$ of all samples exceeded $800 \mathrm{MPa}$ except for sample A20 (alloy with a lower content of molybdenum), where this value is lower (see Figure 9). This may be characteristic of this type of alloy, but it may also be a sample with chemical or structural inhomogeneity. However, the values of determined maximal flow stress $\sigma_{\max }$ showed differences (see Figure 9 and Table 3). Alloys with a lower molybdenum content (samples A50 and A20) reached values of $\sigma_{\max }$ over $1100 \mathrm{MPa}$, and alloys with a higher molybdenum content (samples B50 and B20) reached values of $\sigma_{\max }$ more than $1300 \mathrm{MPa}$ (see Figure 9 and Table 3). In the case of sample A20, the chosen strain at compression tests was not sufficient to achieve the maximum flow stress (see Figure 9) and therefore it was not possible to determine the values of $\sigma_{\max }$ and $\varepsilon_{\mathrm{p}}$ (see Table 3 ). Comparing previously published results for non-alloyed $\mathrm{Ni}_{3} \mathrm{Al}$-based alloys [16,17], it is clear that alloys investigated in this paper evinced significantly higher values of mechanical characteristics in compression. Nonalloyed alloys after directional solidification also reached the maximal flow stress approx. $1100 \mathrm{MPa}$, but at a strain of 0.15 and a yield strength of 530-580 MPa.

The several strengthening mechanisms are applied for Ni-based alloys. It is solid solution strengthening, $\gamma^{\prime}$ phase precipitation and further strengthening by excluded particles. In the case of prepared experimental alloys, we assume that all the mentioned mechanisms are applied under mechanical stress. Good mechanical properties in pressure testing at elevated temperatures are also achieved due to the existence of a directed structure and the presence of fine Mo-rich particles distributed in the structure, which was achieved by electron beam zone melting method. This is evident in type B alloys with a higher Molybdenum content, which achieved values of $\sigma_{\max }$ more than $1330 \mathrm{MPa}$. 
The question is whether these low-alloy materials with highly fusible metals would be applicable to additive technologies. There is now only interest in typical Ni alloys, such as Nickel-based super alloys (Inconel 625 and 718, DL125L), which are tested as materials suitable for PBF-based AM processes or Selective laser melting 3D printing [18-21].

\section{Conclusions}

Castings were prepared by the method of induction melting and centrifugal casting, which were subsequently re-melted by the method of electron zone melting with a suspended zone. The prepared alloys can be considered as composites, because their microstructure consists of $\gamma-\mathrm{Ni}$, intermetallic compound $\gamma^{\prime}-\mathrm{Ni}_{3}(\mathrm{Al}, \mathrm{Mo})$ as matrix and Mo-rich phases in fibrous, or lamellar, shape. The mechanical characteristics of the alloys were tested at the temperature of $800{ }^{\circ} \mathrm{C}$ and strain rate $5 \cdot 10^{-2} \mathrm{~s}^{-1}$. It was found that the yield strengths of both types of alloys reached approx. $800 \mathrm{MPa}$. The different molybdenum content was reflected in the values of the maximal flow stress. Alloys with a higher molybdenum content reached higher values of the maximal flow stress, approx. $1300 \mathrm{MPa}$. The alloys were multiphase and their structure was very complex. The grains in the samples were strongly oriented in the direction of solidification.

Author Contributions: Writing—original draft preparation, J.M.; writing-review and editing K.S.; investigation (the preparation of alloys, metallographic analysis, mechanical testing of alloys), P.K., R.K., I.S. and J.R. All authors have read and agreed to the published version of the manuscript.

Funding: This paper has been completed in association with project no. SP2022/68 "Specific Research in the Metallurgical, Materials and Process Engineering", project no. SP2022/65 "Materials based on non-ferrous metals-preparation, processes for improving their properties, area of application and the possibilities of recycling selected types of waste and project reg. no. CZ.02.1.01/0.0/0.0/17_049/0008407 "Innovative and additive manufacturing technology—new technological solutions for 3D printing of metals and composite materials" financed by Structural Funds of the European Union.

Institutional Review Board Statement: Not applicable.

Informed Consent Statement: Not applicable.

Data Availability Statement: The data presented in this study are available on request from the corresponding author.

Acknowledgments: We would like to thank M. Madaj, D. Petlák and M. Pohludka for processing part of the experimental materials.

Conflicts of Interest: The authors declare no conflict of interest.

\section{References}

1. Stoloff, N.S.; Sikka, V.K. Physical Metallurgy and Processing of Intermetallic Compounds, 1st ed.; Springer Science \& Business: Boston, MA, USA, 2012; 684p.

2. Sikka, V.K.; Deevi, S.C.; Viswanathan, S.; Swindeman, R.W.; Santella, M.L. Advances in processing of Ni3Al-based intermetallics and applications. Intermetallics 2000, 8, 1329-1337. [CrossRef]

3. Wessel, J.K. Handbook of Advanced Materials: Enabling New Designs, 1st ed.; John Wiley \& Sons, Inc.: Hoboken, NJ, USA, 2004; 645p.

4. Kong, Z.; Li, S. Effect of temperature and stress on the creep behavior of a Ni $\mathrm{Al}_{3}$ base single crystal alloy. Prog. Nat. Sci. 2013, 2, 205-210. [CrossRef]

5. Jiang, L.; Li, S.; Wu, M.; Han, Y. Grain competition mechanism of Ni ${ }_{3} \mathrm{Al}$-based single crystal superalloys IC6SX. Mater. Sci. Forum 2013, 747-748, 205-210.

6. Jiang, L.; Li, S.; Han, Y. Investigation on selection crystal behavior of a $\mathrm{Ni}_{3} \mathrm{Al}$-based single crystal superalloy IC6SX. Procedia Eng. 2012, 27, 1135-1140. [CrossRef]

7. Li, P.; Li, S.; Han, Y. Influence of solution heat treatment on microstructure and stress rupture properties of a $\mathrm{Ni}_{3} \mathrm{Al}_{\text {base }}$ single crystal superalloy IC6SX. Intermetallics 2011, 19, 182-186. [CrossRef]

8. Jiang, L.; Dou, X.; Wu, M.; Cai, M. Microstructure and heat treatment for $\mathrm{Ni}_{3} \mathrm{Al}$-based single crystal alloy with different crystal orientation. Prog. Nat. Sci. Mater. Int. 2020, 30, 533-538. [CrossRef]

9. Jiang, L.; Cui, Y.; Wuc, M.; Li, S.; Han, Y. Creep behaviour and dislocation mechanism of a Ni ${ }_{3} \mathrm{Al}$ based single crystal alloy IC6SX at $760{ }^{\circ}$ C. Prog. Nat. Sci. Mater. Int. 2021, 31, 755-761. [CrossRef] 
10. Jiang, L.; Dou, X.; Wu, M. Effect of Stress on Creep Behavior of Single Crystal Alloy IC6SX at $980{ }^{\circ}$ C. Int. J. Photoenergy 2020, 2020, 8844874. [CrossRef]

11. ASM International. Ni-Mo Phase Diagram. In ASM Alloy Phase Diagrams Database [Online]; ASM International: Materials Park, $\mathrm{OH}, \mathrm{USA}, 2009$.

12. Li, F.; Li, S.; Wu, Y.; Jiang, L.; Han, Y. Thermal cycle fatigue behaviors of a single crystal $\mathrm{Ni}_{3} \mathrm{Al}$ base alloy. Procedia Eng. 2012, 27, 1141-1149. [CrossRef]

13. Ishak, M.; Takagi, H. The characteristics of unidirectional solidified Ni-Al-Mo alloys. Mater. Werkst. 2012, 43, 416-420. [CrossRef]

14. Zhang, J.F.; Shen, J.; Shang, Z.; Wang, L.; Fu, H.Z. Elevated temperature tensile properties and deformation of directionally solidified NiAl-Mo in-situ composites. Mater. Charact. 2015, 99, 160-165. [CrossRef]

15. Zhou, S.H.; Wang, Y.; Chen, L.-Q.; Liu, Z.-K.; Napolitano, R.E. Solution-based thermodynamic modeling of the Ni-Al-Mo system using first-principles calculations. Calphad 2014, 46, 124-133. [CrossRef]

16. Malcharcziková, J.; Kursa, M.; Pohludka, M.; Kawulok, P.; Rusz, S.; Jordanovová, V. Deformation behaviour of Ni $\mathrm{Al}_{3}$ based alloys in compression. In Proceedings of the 25th International Conference on Metallurgy and Materials METAL 2016, Brno, Czech Republic, 25-27 May 2016; Tanger: Ostrava, Czech Republic, 2016; pp. 1486-1491.

17. Malcharcziková, J.; Kursa, M.; Pohludka, M.; Kawulok, P.; Gratza, P. High temperature mechanical properties of Ni $\mathrm{Al}_{3}$ and $\mathrm{Ni}_{3} \mathrm{Al}-\mathrm{Mo}$ alloys in compression. In Proceedings of the 26th International Conference on Metallurgy and Materials METAL 2017, Brno, Czech Republic, 24-26 May 2016; Tanger: Ostrava, Czech Republic, 2017; pp. 1874-1880.

18. Ngo, T.D.; Kashani, A.; Imbalzano, G.; Nguyen, K.T.Q.; Hui, D. Additive manufacturing (3D printing): A review of materials, methods, applications and challenges. Compos. Part B 2018, 143, 172-196. [CrossRef]

19. Qian, D.; Xue, J.; Zhang, A.; Li, Y.; Tamura, N.; Song, Z.; Chen, K. Statistic study of ductility-dip cracking induced plastic deformation in polycrystalline laser 3D printed Ni-based superalloy. Sci. Rep. 2017, 7, 2859. [CrossRef] [PubMed]

20. Xia, M.; Gu, D.; Yu, G.; Dai, D.; Chen, H.; Shi, Q. Selective laser melting 3D printing of Ni-based superalloy: Understanding thermodynamic mechanisms. Sci. Bull. 2016, 13, 1013-1022. [CrossRef]

21. Li, Y.; Chen, K.; Tamura, N. Mechanism of heat affected zone cracking in Ni-based superalloy DZ125L fabricated by laser 3D printing technique. Mater. Des. 2018, 150, 171-181. [CrossRef] 